elektrischen Funken beliebig regeln und jeden Funkenwechsel einzeln hervortreten lassen. Einem jeden Funkenwechsel entspricht eine Lichterscheinung; und wenn man die Entladungen so auf einander folgen lässt, dass man sie deutlich von einander unterscheiden kann, so fliessen auch die Lichterscheinungen nicht mehr ineinander über, sondern das Auge unterscheidet deutlich die abwechselnd auf einander folgenden dunkeln und lichten Schichten. Wochenztg. 1854. No. 11.)

(Polyt. $B$.

\title{
Neues Verfahren zur Bereitung des Phosphors.
}

Nach Cari-Mantrand bringt man ein Gemisch von gleichen Theilen Knochenasche und Holzkohle in einer Porcellanröhre zum Glühen und leitet durch die eine Oeffnung trocknes salzsaures Gas hinzu; am andern Ende befestigt man ein gebogenes Glasrohr, welches in Wasser taucht. Sobald die Gasentwickelung beginnt, entweicht Kohlenoxydgas und die Phosphordämpfe verdichten sich im Wasser. $3 \mathrm{CaO}+\mathrm{PO}^{5}+8 \mathrm{C}+3 \mathrm{ClH}=3 \mathrm{CaCl}+$ $8 \mathrm{CO}+3 \mathrm{HO}+\mathrm{P}$. Keine Spur von phosphorsaurem Kalk soll in der Röhre zurückbleiben. Durch Hinzuleiten von Chlorgas erfolgte die Zersetzung noch schneller und ohne Verlust an Phosphor, da der Chlorphosphor in der Hitze sich zerlegt, dahingegen bei der Anwendung von Chlorwasserstoffgas, wenn die Hitze nicht immer stark genug ist, etwas Phosphorwasserstoffgas entweicht. (Moniteur industriel. 1854. No. 1861. - Polyt. Centrbl. 1854. No. 14. p. 885.)

$M r$.

\section{Ueber Benutznng des Aluminiums.}

Das. Aluminium bildet mit Kohle eine sehr beständige, sehr harte und wahre Verbindung, und eignet sich daher sehr gut zur Erzeugung von Stahl. Es dient nun in Chenot's System der Stahlbereitung dazu, den Kohlenstoff zu fixiren, giebt einen sehr weissen, harten Stahl, der sich schmieden lässt, während die Stahle von Silicium einen körnigen Bruch haben und spröde sind. Bei 5 bis 6 Procent Siliciumgehalt lassen sich die Metalle pulvern wie Gesteine. (Compt. rend. T.39. - Chem.-pharm. Centrbl. 1854. No. 49.)

$B$. 